\title{
LA NARRATIVA PUNEÑA DE HÉCTOR TIZÓN O LA CARENCIA ONTOLÓGICA DE LIBERTAD
}

Marta Elena Castellino

doi.org/10.15452/SR.2020.20.0002

Universidad Nacional de Cuyo

Argentina

martaelenac15@gmail.com

Resumen. El proyecto escriturario de Héctor Tizón (1929-2012) constituye uno de los más sólidos y valiosos en la literatura argentina de la segunda mitad del siglo XX; en él es posible distinguir una primera etapa, signada por la omnipresencia de la Puna (del quechua «tierra elevada»), altiplanicie ubicada a más de 3.500 metros sobre el nivel del mar en la Provincia de Jujuy (República Argentina) y alejada de los centros urbanos; realidad geográfica cuyas características ingresan en el campo de lo ominoso y que pesan sobre el hombre determinando un mundo clauso, descripto en el texto con obsesiva minuciosidad. A ello puede agregarse la recurrencia a la oralidad en la construcción textual y al folklore y la historia como depositarios de la memoria colectiva; el fragmentarismo y la proliferación de voces y versiones en una buscada ambigüedad y, como dice Tendler, la «instauración de un tipo de verosímil no realista, verosimilitud mágica o mítica». El hombre que la habita se debate, sobre todo en las primeras novelas del autor argentino, entre la añoranza de un pasado arcádico y feliz y un presente de marginación y pobreza, «excluidos de la comunicación normal con sus semejantes, afectados por el alcohol, la locura y el peso irremediable de los recuerdos; y una problemática [...] donde la soledad individual [...] entabla un agudo contrapunto con una presentación agudamente pesimista de las condiciones sociales», como añade Lagmanovich. Pero más que una cuestión de índole social, parece pesar sobre estos hombres una condena casi bíblica, que es histórica (marginación política de la zona por el estado liberal), pero que también tiene que ver con la naturaleza herida del hombre, influida por una concepción que tiene tanto del fatalismo indígena como del pensamiento existencialista, pasando por el determinismo ambiental decimonónico. Todas estas incitaciones confluyen en una concepción que descree de la libertad individual y que se manifiesta en las novelas incluidas como corpus de este trabajo: Fuego en Casabindo (1969); El cantar del profeta y el bandido (1972); Sota de bastos, caballo de espadas (1975) y El hombre que llegó a un pueblo (1988), en las que se opera «la transfiguración y universalización de lo tradicional», tanto a nivel temático-ideológico como estilístico. 
Palabras clave. Literatura argentina. Novela argentina. Héctor Tizón. Narrativa puneña. Libertad.

Abstract. Puna Narrative of Héctor Tizón or Ontological Lack of Freedom. The writing project of Héctor Tizón (1929-2012) is one of the most solid and valuable works in the Argentinean literature of the second half of the $20^{\text {th }}$ century. It is possible to distinguish an initial stage, with the omnipresence of the Puna (from the Quechua "high land"), a plateau lying more than 3500 meters above sea level in the Province of Jujuy (Argentina) and far away from urban centres; geographical reality whose characteristics enter in the field of ominous and that weigh on man determining a closed world, described in the text with many obsessive details. One could add the recurrence to orality in textual construction and the folklore and history as custodians of collective memory; the fragmentarism and proliferation of voices and versions in a sought-after ambiguity and, as commented by Tendler, the "establishment of a kind of unrealistic plausibleness, magical or mythical plausibility". The man who inhabits this world is debated, particularly in the first novel of the Argentinean author, between an archaic and happy past and a present of marginalization and poverty, "excluded from normal communication with their fellows, affected by alcohol, madness and irretrievable weight of memories; and a problematic [...] where individual loneliness [...] engages in a sharp counterpoint with an acutely pessimistic presentation of social conditions", in Lagmanovich's words. However, more than a social issue, an almost biblical condemnation seems to weigh on these men, which is historical (political marginalization of the area by the liberal state), but also related with the wounded nature of man, influenced by a conception that has both indigenous fatalism, and existentialist thought, through the $19^{\text {th }}$ century environmental determinism. All these incitements converge in a conception that discredits individual freedom and that is manifested in the novels included as corpus of this investigation: Fuego en Casabindo (1969); El cantar del profeta y el bandido (1972); Sota de bastos, caballo de espadas (1975) and El hombre que llegó a un pueblo (1988), in which "the transfiguration and universalization of the traditional" is operated, both at the thematic-ideological and stylistic levels.

Keywords. Argentine literature. Argentine novel. Héctor Tizón. Puna narrative. Freedom. 


\section{Introducción}

Héctor Tizón (Rosario de la Frontera, Salta, 1929-San Salvador de Jujuy, 2012) ${ }^{1}$ se constituye en un conspicuo representante de una promoción narrativa argentina que -surgida promediando el siglo XX- da expresión a una nueva forma de «regionalismo», y en la que se cuentan también algunas figuras tan notorias como las de Juan José Saer o Antonio Di Benedetto, por citar solo dos ejemplos pertenecientes a distintos ámbitos geográficos (el Litoral y Cuyo, respectivamente). Igualmente, su proyecto escriturario-nos permite ver cómo las regiones culturales exceden las fronteras políticas, son supranacionales, tal como ocurre con la denominada «región andina» y, en particular, con la cultura del Altiplano.

Nacidos en provincia, estos escritores textualizan su entorno, pero no dentro de los moldes del realismo literario, como ocurría con los primeros regionalistas de las décadas del 20 y del 30, sino que vuelcan en su escritura todas las renovaciones artísticas que la literatura argentina (e hispanoamericana) ha ido experimentando con el correr del siglo XX (influencia de la narrativa norteamericana, del nouveau roman, pero también del realismo mágico, etc.). Del mismo modo, el tópico de la marginación comienza a ser cada vez más operante, tanto en la narrativa de ambiente urbano como rural.

En el amplio espectro de sus producciones individuales puede aparecer «una intensa reflexión teórica sobre sus propias condiciones de producción», junto con «una sostenida voluntad de despegue referencial y de ruptura con todo efecto meramente representativo» (Amar Sánchez y otros, 1982: 626). Igualmente, algunos autores «comparten, sobre todo, una intensa preocupación formal y estilística, y una cuidadosa reflexión sobre el lenguaje, que se exacerba precisamente allí» donde los escritores «coinciden en su trabajo de rescate histórico» (Amar Sánchez y otros, 1982: 628).

En ese contexto, el proyecto escriturario de Héctor Tizón aparece como uno de los más sólidos y valiosos en la literatura argentina de la segunda mitad del siglo $\mathrm{XX}^{2}$; en él es posible distinguir una primera etapa, signada por la omnipresencia de la Puna (del quechua «tierra elevada»), altiplanicie ubicada a más de 3.500 metros sobre el nivel del mar en la Provincia de Jujuy (República Argentina) y alejada de los centros urbanos; realidad geográfica cuyas características ingresan en el campo de lo ominoso y que pesan sobre el hombre determinando un mundo clauso, descripto en el texto con obsesiva minuciosidad.

1 «Licenciado en Derecho, fue ministro, diplomático y juez del Tribunal Supremo jujeño, y vivió en México, París, Milán y Madrid, si bien siempre volvió a Jujuy. Publicó sus primeros cuentos en el periódico El Intransigente, y llegó a dirigir el diario Proclama, antes de tener que exiliarse a España por razones políticas (el golpe militar que inició el Proceso de Reorganización Nacional en Argentina), donde trabajó en diversas editoriales y medios. En 1960 apareció en México su primer libro, un compendio de relatos titulado $A$ un costado de los rieles. Casado con la filóloga Flora Guzmán, recibió numerosos galardones, entre ellos varios premios Konex, y fue Caballero de la Orden de las Artes y las Letras de Francia y miembro de la Academia de Letras argentina. Cultivó varios géneros narrativos: novela (Fuego en Casabindo, 1969; El hombre que llegó a un pueblo, 1988; La mujer de Strasser, 1997; etc.), cuento (El jactancioso y la bella, 1972; El traidor venerado, 1978; El gallo blanco, 1992), literatura juvenil (El viaje, 1988), y también se acercó al ensayo (Tierras de frontera, 2000). Su literatura fue inspirada en gran parte por la tradición oral del pueblo que lo vio nacer» (http://www. lecturalia.com/autor/306/hector-tizon). Participó igualmente en el movimiento cultural jujeño, a través de su participación en la creación del grupo literario Tarja. También durante su estadía en México editó la revista Síntesis, encargada de difundir aspectos del movimiento intelectual y literario y creó, junto a otros intelectuales, el Taller del Teatro, que funcionaba en los altos del café «Chufas», «al que concurría cada tanto Ernesto Cardenal» (Amar Sánchez; Stern; Zubieta, 1982: 635).

2 Como sus rasgos más destacados se pueden mencionar, con David Lagmanovich, los siguientes: «una atmósfera frecuentemente alucinante, en la que no obstante se reconocen con frecuencia elementos de la vida en los parajes fronterizos de las comarcas argentinas más alejadas de los grandes centros urbanos; [y] unos personajes marginales y marginados» (1974: 227). 
Luego, a partir de sucesivas experiencias vitales (entre las que podría contarse la vivencia del exilio ${ }^{3}$ ) tanto como estéticas, la narrativa de Tizón parece abrirse a horizontes más amplios o, al menos, indeterminados, aunque sin perder del todo la referencia a ese «centro» mítico que es el territorio de su niñez.

Como características de su universo narrativo podríamos mencionar -sobre todo pero no excluyentemente- en su primera etapa la recurrencia a la oralidad en la construcción textual y al folklore y la historia como depositarios de la memoria colectiva; el fragmentarismo y la proliferación de voces y versiones en una buscada ambigüedad y la «instauración de un tipo de verosímil no realista, verosimilitud mágica o mítica» (Tendler, 1982: 159). El hombre que habita la tierra puneña se debate, sobre todo (repito) en las primeras novelas del autor argentino, entre la añoranza de un pasado arcádico y feliz y un presente de marginación y pobreza, «excluidos de la comunicación normal con sus semejantes, afectados por el alcohol, la locura y el peso irremediable de los recuerdos; y una problemática [...] donde la soledad individual [...] entabla un agudo contrapunto con una presentación agudamente pesimista de las condiciones sociales» (Lagmanovich, 1974: 227).

Pero más que una cuestión de índole social, parece pesar sobre estos hombres una condena casi bíblica, que es histórica (marginación política de la zona por el estado liberal), pero que también tiene que ver con la naturaleza herida del hombre, influida por una concepción que tiene tanto del fatalismo indígena como del pensamiento existencialista, pasando por el determinismo ambiental decimonónico.

Todas estas incitaciones confluyen en una concepción que descree de la libertad individual y que se manifiesta en las novelas incluidas como corpus de este trabajo: Fuego en Casabindo (1969); El cantar del profeta y el bandido (1972); Sota de bastos, caballo de espadas (1975) y El hombre que llegó a un pueblo (1988), en las que se opera «la transfiguración y universalización de lo tradicional», tanto a nivel temático-ideológico como estilístico.

\section{Una cosmovisión particular}

Sabemos que el concepto tradicional, tomista ${ }^{4}$, de «libertad» entra en crisis con la modernidad y, sobre todo -ya en el siglo XX- con el pensamiento existencialista ${ }^{5}$.

«El hombre está condenado a ser libre», decía el filósofo francés Jean-Paul Sartre, uno de los máximos exponentes del existencialismo. Esto significa que la libertad es inherente a la condición humana y que, por ello, el hombre es absoluto responsable del uso que haga de ella.

3 Emiliano Matías Campoy destaca precisamente la importancia de su alejamiento de la tierra natal, como un «viaje que por cierto acarrearía notables cambios en su forma de concebir la literatura, inaugurando una segunda etapa en su producción artística [...]. Con el retorno de la democracia, Tizón decidió volver a la Argentina, más precisamente a Yala, esperanzado, como tantos otros, de reencontrarse con los suyos. Pero ni él ni los otros (ni siquiera su pueblo, ese paisaje que añoraban sus ojos y recreaba su imaginación) eran ya los mismos. A partir de ese (des)encuentro Tizón comienza a transitar la última etapa de su producción literaria, que depararía muchas obras pero carentes de la intensidad, de la fuerza narrativa de las primeras» (Campoy, 2018: 395). Por mi parte, si bien los fundamentos que expone Campoy son sólidos, prefiero considerar solo dos etapas, a los efectos de este trabajo.

4 Santo Tomás de Aquino define la libertad como la ausencia de coacción; es el poder de la voluntad humana para hacer una cosa o no hacerla, o bien para elegir entre dos cosas.

5 Como señala Carlos Astrada, «En el caso del existencialismo concierne mostrar que no es una 'filosofía de la crisis', en el significado de producto de una situación anómala, de desvío respecto a un rumbo que le hubiera sido prefijado al pensamiento occidental, sino que él implica una crisis de la filosofía, un cambio de derrotero en el planteamiento y absolución de sus problemas fundamentales (el problema del ser, de la verdad, del tiempo de la trascendencia)» (Astrada, 1949: 355). 
La reivindicación sartriana de la libertad es tan radical que le lleva a negar cualquier género de determinismo ${ }^{6}$.

El existencialismo, al trocar el concepto de esencia por el de existencia, deja al hombre librado a una suerte de indeterminación ontológica, que es fuente de angustia. El mismo Sartre, al referirse a las consecuencias inevitables de la libertad radical menciona tres: la angustia, el desamparo y la desesperación. La angustia «no es por ningún motivo concreto, ni de ningún objeto externo, es miedo de uno mismo, de nuestras decisiones, de las consecuencias de nuestras decisiones. Es la emoción o sentimiento que sobreviene con la conciencia de la libertad». El desamparo, por su parte, «es una consecuencia de la conciencia de la radical soledad en la que nos encontramos cuando decidimos: el elegir es inevitable, personal e intransferible. Finalmente, la desesperación sobreviene cuando se percibe -indubitablemente- que «sólo podemos contar con lo que depende de nuestra voluntad: el mundo no se acomoda necesariamente a nuestra voluntad, siempre hay factores imprevistos, siempre es posible que se trueque nuestra intención en algo totalmente distinto a lo previsto» (Echegoyen Olleta, 1997).

De alguna manera, la impronta del pensamiento existencialista es visible en la Generación de 1950 o 19557, en la que podemos encuadrar la obra de Héctor Tizón, sin que él sea, de hecho, un existencialista. Así, podemos descubrir huellas de ese sentimiento de desamparo radical que sobrecoge al hombre, junto con una visión desesperanzada de la condición humana que implica, de suyo, un cuestionamiento de la noción misma de libertad.

Del mismo modo, es notorio el peso de una cosmovisión particular: la del hombre andino, que el filósofo argentino Rodolfo Kusch ${ }^{8}$, en trabajos filosóficos como América profunda (1962) y El pensamiento indígena y popular en América (1977), entre otros, caracteriza en términos del «estar» (por oposición al «ser» propio del hombre occidental, europeo): «El estar se asocia con el ámbito, con el domicilio. En América el estar es un estar siendo; en Europa, en cambio, es un ser estando: parten del ser y pasan al estar, al domicilio» (Pérez, 2003:61) ${ }^{9}$. Además, tanto para el escritor como para el filósofo estas dos concepciones antedichas -de lo estático indígena y lo dinámico occidental- se asocian con el ámbito geográfico:

6 Las doctrinas que niegan la libertad reciben el nombre de determinismos. Se puede hablar de distintos tipos de determinismo: biológico (según el cual las personas y sus capacidades físicas y psicológicas dependen de su raza, nacionalidad, etc.); social (según el cual es la sociedad, más precisamente el grupo social al que se pertenece, el que determina la conducta del individuo); geográfico o ambiental (que habla del peso del medio ambiente, de la naturaleza, sobre el hombre), etc.

7 Acerca de la impronta del pensamiento existencialista, apunta Coly (Coly, 2012: 347) que «Si bien es cierto que el existencialismo hace su entrada y marca su influencia en Argentina a partir de la difusión de los textos de Sartre y Camus, no es menos cierto que este país siempre se ha mostrado abierto a la filosofía de la existencia». Y agrega que «Fiel a las enseñanzas de Heidegger, el profesor Astrada reivindica 'el tomar como punto de partida de toda reflexión filosófica la desnuda facticidad de la existencia humana (dasein), expresada en su estar-en-el-mundo'» (Coly 2012: 185). Otro pensador argentino, Miguel Ángel Virasorio, plantea en su libro La libertad, la existencia y el ser (1942) el problema de la dialecticidad del existencialismo. Virasorio parte del principio según el cual el ser es inherente a todo dasein, para desembocar en que la libertad, en cuanto proyecto absoluto de toda existencia, consiste en realizarse plenamente (Coly 2012: 185).

8 Kusch afirma esa «bifrontalidad de lo americano», escindido en dos vertientes: la línea occidental y la indígena; ambas, en una suerte de equilibrio inestable gestan un tercer elemento: el mestizo, ser que «sufre un desacomodamiento ontológico que debe resolver, dando solución coherente a su doble vertiente» (cf. Borda de Rojas Paz, 1986: 59).

9 La importancia del descubrimiento [de América] estriba en el hecho de que es el encuentro entre dos experiencias del hombre. Por una parte la del ser, como dinámica cultural, cuyo origen se remonta a las ciudades medievales que adquiere madurez hacia el siglo XVI. Por la otra, es la experiencia del estar, como sobrevivencia, como acomodación a un ámbito por parte de los pueblos precolombinos (Kusch, 1962: 146). 
Quizá sólo por razones estáticas cabe entender que las culturas indígenas de Sudamérica se hayan quedado en la meseta. Y también por el mismo motivo, se entiende lo occidental como dinámico y propio de las llanuras [...] y siendo, como es, la cultura quichua una cultura de meseta, sometida a la naturaleza y encuadrada dentro del ámbito de su rejilla mágica, está sumergida en eso que llamamos la ira de dios, la cual esconde una emoción mesiánica, que engendra un comportamiento espiritual (Kusch, 1962: 104).

Como dice Kusch, «la naturaleza, está primero que el hombre [...] América continúa inmersa en ese gran fondo irracional que es la naturaleza». Tanto Kusch como Tizón destacan el contenido en cierto modo esotérico que esta aproximación a la realidad americana implica, y la mediación-revelación del arte se presenta como apta para su exploración: en palabras de Kusch, para dar cuenta de la bifrontalidad de nuestra cultura y de la categoría de «lo tenebroso» (puede leerse en esta afirmación una implícita referencia a ciertos umbrales iniciáticos que podrían a su vez relacionarse con el mito y su función arquetípica respecto de las cotidianas acciones humanas).

Entre la tensión de lo sagrado y lo profano, cuando Occidente se refugia en la ciencia, el indígena, el campesino, en América, se refugia en la magia. Como consecuencia, «El sudamericano, establecido en su estar, se rebela contra la imposición científico-racional [...] La cultura letrada está divorciada de América. Por eso Kusch en su búsqueda de lo americano no recurre a la cultura letrada sino a la popular y a la nativa». Entonces, «El pensamiento americano no es conocimiento intelectual, no se trata de un conocimiento enciclopedista, sino que está apoyado en un saber popular» (Pérez, 2003: 61-62).

Esta cosmovisión arcaica, de algún modo entra en conflicto o se articula con la religiosidad popular de cuño hispánico y genera en la obra tizoniana una tensión no resuelta en la que se debaten cuestiones teológicas claves como el tema del mal, la redención y la culpa, como veremos a propósito de El hombre que llegó a un pueblo. La presencia de elementos provenientes de un trasfondo predominantemente vétero- testamentario, presentes a través de símbolos, referencias a figuras bíblicas, alusiones, citas concretas y «malversaciones» del texto canónico puestas en boca de los personajes, constituye otro meridiano semántico de cabal importancia para comprender la obra del autor argentino.

A partir de este trasfondo de pensamientos se delinean las principales características de la narrativa tizoniana, como veremos, tarea a la que el propio escritor se refiere en estos términos, que delinean su figura como el «cronicador de la Puna», de un mundo en decadencia:

Creí entonces que era mi deber rescatar y conservar lo que estaba destinado a desaparecer con el progreso. Es decir, yo también me contagié con el síndrome del anticuario: coleccionar objetos que se perdían o estaban condenados a perderse; o del folklorista, exhortando a que se crearan archivos, registros, y museos de tradiciones populares.

Ahora estoy convencido de que nada sobrevive a sí mismo y que eso no está bien ni mal; que eso es así, como el amor y la muerte. Que ningún voluntarismo podrá salvar lo que se apaga por extinción. Pero también, que ninguna cultura se extingue de pronto y del todo, sino que su esencia y aun sus formas se adhieren y contagian y algo o mucho de ellas sobrevive en lo que inmediatamente le sigue y que todos somos hijos de nuestros abuelos moribundos o muertos y nada es puro (Tizón, 1998a: X). 


\title{
3. La narrativa puneña de Héctor Tizón
}

Como recuerda Adrián Pablo Massei ${ }^{10}$, tras la aparición de El cantar del profeta y el bandido (su segunda novela), en 1972, Tizón había manifestado su propósito de elaborar una serie novelística en tres ciclos, en los que quedara registrado ese mundo cerrado, el puneño, con su historia, sus hombres y epopeyas, desde el siglo XVIII hasta la llegada del ferrocarril. A este propósito corresponden las siguientes novelas: Fuego en Casabindo (1969), El cantar del profeta y el bandido y Sota de bastos, caballo de espadas (1981), en las que se textualizan tres momentos históricos claramente diferenciados. A continuación, aparecerá La casa y el viento (1984) y El hombre que llegó a un pueblo (1988), que son, respectivamente, la novela del exilio y del regreso y que marcan el inicio de una segunda etapa en la obra de Héctor Tizón, más universal y también más individual, en cuanto al punto de vista adoptado para encarar la búsqueda de sentido, que da el tono general a toda la narrativa del jujeño.

Esto es así porque los personajes del jujeño, que son también los de esa Puna olvidada, callada y sola, parecen de antemano predeterminados, inmersos en el agobio de un mundo que el novelista funda desde sus primeras obras.

Al plantear las relaciones entre el «país real» y las comarcas imaginarias de la literatura que construye la narrativa de Tizón, conviene recordar el juicio que al respecto formula Leonor Fleming:

\begin{abstract}
¿Y qué es la Puna? Esa alta meseta andina, árida y fría, que comienza en la frontera noroeste de la Argentina y continúa en el altiplano boliviano, atravesada por cadenas de volcanes, con grandes salares y algunas lagunas, cruzada por la Quebrada de Humahuaca. Pero esa es y no es la Puna de Tizón, porque la Puna de Tizón es sobre todo una invención. Sin embargo, esa Puna literaria existe porque los espacios literarios son espacios reales. Aunque los cartógrafos no los detecten, inciden en la realidad y la modifican (Fleming, 2006).
\end{abstract}

ElmismoTizón lo diceen uno de sus ensayos: «La Puna, el gran desiertolunar, cálidoy frío más que un lugar geográfico es una experiencia» (Tizón, 2000: 179). Y continúa Fleming: «El espacio literario puede basarse en la geografía, incluir sus topónimos y los rasgos de su paisaje y de su gente, pero es más amplio y ubicuo. Leyendo a Tizón podemos conocer la Puna sin haber pisado nunca Jujuy» (Fleming, 2006). Tizón funda literariamente su mundoy lo sitúa en relación con una mítica Edad de Oro -como dijimos- en la página inicial de Fuego en Casabindo, la primera de sus novelas:

Aquí la tierra es dura y estéril; el cielo está más cerca que en ninguna otra parte y es azul y vacío. No llueve, pero cuando el cielo ruge su voz es aterradora, implacable, colérica. Sobre esta tierra, donde es penoso respirar, la gente depende de muchos doses. Ya no hay aquí hombres extraordinarios y seguramente no los habrá jamás. Ahora uno se parece a oro como dos hojas de un mismo árbol y el paisaje es igual al hombre. Todo se confunde y va muriendo.

10 «[...] Tizón proyecta sus tres primeras novelas como una trilogía histórica en la que pretende dejar registro de la presencia indígena en la Puna, de su lucha por sobrevivir en un medio geográfico y climático hostil, así como de la llegada del progreso y de su encuentro con las tradiciones autóctonas. Su novela del adiós, La casa y el viento, también se postula como registro de esa realidad que el personaje desea grabar en su mente, antes de marchar rumbo al exilio. Finalmente, su novela del retorno, El hombre que llegó a un pueblo, nos devuelve a la aridez del altiplano y a la llegada de una carretera que no se sabe muy bien adónde conduce, pero que acarrea profundos cambios en los modos de vida de los habitantes del lugar» (Massei, 1998: 15-16). A propósito de esta última novela, cf. Marta Elena Castellino. «El tema del mal, la redención y la culpa en $E l$ hombre que llegó a un pueblo, de Héctor Tizón», que postula otra interpretación al conflicto presentado, más allá de la dialéctica tradición / progreso. 
Los que escucharon hablar a los más viejos, dicen que no siempre reinaron la oscuridad y la pobre$\mathrm{za}$, que hubieron aquí grandes señores, hombres sabios que hablaban con elocuencia, mujeres que parían hijos de ánimo esforzado, orfebres de la madera, de la arcilla y de los metales de paz y guerra, músicos, pastores de grandes majadas y sacerdotes que sabían conjurar los excesos divinos [...] Pero eso ocurrió en otros tiempos [...] La última batalla -por el dominio de estos páramos- quizá fuera consecuencia de aquel vago recuerdo de grandeza. Pero, de todos modos, de este combate nada quedó. Salvo unos cantares y muchos muertos, algunos de cuyos cuerpos errantes fueron encontrados luego, lejos del campo de la lucha (Tizón, 1998c: 335).

He prolongado la cita para poner de relieve esos rasgos definitorios: ante todo, el peso de lo ominoso en relación con una naturaleza que debe ser conjurada; de allí la impronta que el mundo de las creencias supersticiosas ejerce sobre los hombres (entre ellas, la que proporciona el núcleo argumental de esta novela: la creencia de que un alma no puede descansar en paz hasta que no mire de frente a su matador ${ }^{11}$ ); el mito de la edad de oro, cuyo fin se vincula históricamente con el combate de Quera (1875), librado por la posesión de las tierras que reivindicaban como propias los antiguos habitantes, frente al gobierno nacional que pretendía venderlas como tierras fiscales, con el resultado de una gran mortandad de los indígenas.

De todos modos, la decadencia de la zona había comenzado mucho antes cuando con la definición de las fronteras del estado nacional promediando el siglo XIX y la creciente importancia de la ciudad-puerto, Buenos Aires, las rutas comerciales se desplazaron radicalmente, abandonando el antiguo camino al Alto Perú que atravesaba estas zonas ${ }^{12}$ y decretando la decadencia de este pueblo, «un pueblo que andaba a gatas por esta tierra seca y dura y que antes había sido capaz de crear más de dos mil cantares» (Tizón, 1998a: 339). Finalmente, la memoria colectiva como reservorio de esta pasada grandeza, y la importancia de la oralidad, aludida a través de los «cantares» populares.

Este ámbito geográfico es concebido, como señala Leonor Fleming, a partir de «La experiencia de una tierra de frontera, de un mundo marginado» (2006). La frontera se concibe aquí en relación con los conceptos de centro / periferia, analogados a los de civilización / barbarie (expuesto por Domingo Faustino Sarmiento en su clásico Facundo) y tradición / progreso. Este paisaje -siempre según Fleming- «impone no sólo asuntos y personajes sino, sobre todo, una lengua; una lengua que ese paisaje lleva puesta y que implica una mentalidad» (2006). Porque, como afirma Octavio Paz, «cada tierra es una sociedad: un mundo y una visión del mundo y del trasmundo» (Paz, 1971: 116).

Emiliano Matías Campoy, autor de una tesis doctoral sobre la narrativa de Héctor Tizón que aún permanece inédita como tal, ha difundido empero algunos aspectos parciales en diversas publicaciones periódicas, entre ellos, una entrevista al autor jujeño, titulada precisamente

11 Dice Tizón: «Los muertos se despiden; a los muertos les agrada dar un último paseo por los senderos conocidos, acariciar sus herramientas y armas antes de dejarlas, echar una mirada a sus gentes. Generalmente no andan de noche, por temor a los perros; vagan de día, confundidos en la luz. Los que mueren lejos de sus casas tardan más en subir porque deben venir a despedirse» (Tizón, 1998c: 368).

12 «Espacio privilegiado en las rutas coloniales al Alto Perú y aún antes vía de acceso de la dominación incaica y de confrontación o contacto entre los pueblos autóctonos; su apogeo estuvo vinculado al comercio con el virreinato del Perú, y su declive, a la tardía creación del virreinato del Río de la Plata y el monopolio del puerto de Buenos Aires. Límites recientes en términos históricos, impuestos desde Madrid en el último tercio del siglo XVIII y fijados en el XIX cuando después de las Independencias se consolidaron las nuevas naciones, terminan por dividir un territorio que abarcaba una misma cultura andina, haciendo de una región, dos periferias. En el artículo «Equívocos» Tizón lo explica y toma partido «Yo pertenezco justamente a la cultura alto-peruana, no a la cultura del resto del país o pampeana» (Tizón, 1996: 120). 
«Héctor Tizón: el arte como ejercicio de la libertad», en la que se destaca «el rescate de una cosmovisión arcaica, reticente a lo nuevo y doblegada por el progreso», y agrega que este «rescate del legado cultural que conservaba la memoria del menguado esplendor de las llamadas provincias históricas, por su activa participación en las luchas por la independencia nacional, corresponde fundamentalmente a sus primeras obras» (Campoy, 2018: 304-305), como ya se dijo.

En un mundo tal, en que «todo se confunde y va muriendo» no sorprende la coexistencia de vivos y muertos en un mismo espacio ambiguo, que elige la fiesta de «San Santiago» como vértice significativo ${ }^{13}$. Dentro de este espacio tiempo lo más saliente es «el insistente desdibujamiento de los límites que separan a los vivos de los muertos. En su reiteración, esta contigüidad entre la vida y la muerte funda uno de los núcleos de significación más importantes que proponen los textos de Tizón» (Amar Sánchez y otros, 1982: 636-637). La razón es la que dábamos anteriormente respecto de la índole misma del mundo tizoniano; como señalan Amar Sánchez, Stern y Zubieta: estas apariciones o encuentros de índole sobrenatural tienden a mostrar que «el mundo de los vivos, en sí mismo» es el que a raíz de su marginación histórica, se presenta como «un orbe muerto». En resumen, continúan las autoras, «Tizón convoca la historia para presentar un mundo de seres alienados [...] dentro del cual todo acontecer se acepta como una ley mecánica e inevitable» (1982: 637). Sin dejar de reconocer la veracidad de este aserto, se podría agregar que esa convivencia natural entre vivos y muertos es otro elemento característico de esa cosmovisión arcaica que hemos mencionado ${ }^{14}$.

La historia en sí se abre con la llegada del hombre muerto al pueblo (el tuerto), y se cierra con el arribo del victimario (el mayor López) y el esquema argumental de la novela es la crónica de esa búsqueda (asimilada al descenso de Odiseo al Hades, a través del epígrafe), compuesta por una serie de fragmentos sin coherencia temporal clara (a favor de la insistencia en el acto de «recordar») que es referida por la conseja popular:

Cuentan que a uno de estos [muertos en la batalla de Quera] un niño halló en un zanjón, mientras jugaba. Al cadáver le faltaba un ojo; por lo demás, aunque muerto hacía muchos días, parecía tranquilo, sin las rigideces que al cuerpo deja el alma que lo abandona de golpe y huye antes de que se corrompa (Tizón, 1998c: 335).

Proliferan las expresiones como «dicen», cuentan...»; «algunos... otros...». Así, «la orquestación polifónica de esta serie de voces anónimas va dibujando el proceso de plasmación de un relato oral colectivo; y, por el otro, esta suerte de contrapunto coral termina haciendo de la 'voz' la sinécdoque dominante del texto narrativo» (Amar Sánchez y otros, 1982: 638).

Ese pantónimo mencionado -«Puna»- constela una serie de términos geográficos o topónimos como Cochinoca, Yavi, Abra Pampa... pueblos reales diseminados en la geografía del Altiplano, pero también «Ramayoc», comarca inventada por Tizón al modo de Comala o Macondo, pero que espeja la decadente realidad del paisaje y el hombre que lo habita: «El pueblo de casas

13 Es significativa la elección de Santiago, el santo caballero y guerrero, que sirve de interlocutor al alma del jinete muerto, del que ha luchado y muerto violentamente y dice: «[...] 'Yo no he querido esta pelea, señor Santiago, yo no tenía entusiasmo'. Dijo también, aunque sus labios no se movieron, 'yo me estaba muy quieto, pero elegí de este lado’. Santiago no se movía, impasible. [...] Entré en Cochinoca como si tal cosa, espada en mano. Entonces creí darme cuenta de que ello era porque no había perdido la costumbre de matar. Lo mismo ellos. 'Vos galopabas en medio y yo te vi. Reconocí tu sombrero, adornado con una cinta trenzada de granadillas de la Pasión’» (Tizón, 1998c: 353).

14 Un ejemplo de esta particular «contigüidad» podría ser la celebración de la feria de Semana Santa, que, en Yavi, se realiza a las puertas del cementerio. 
abandonadas cuyas techumbres, alabeadas por la ausencia, empezaban a derrumbarse y lucían como caries en esa boca sin risa ni rumores, ni música [...] Solo un milagro haría que la vida perdurase en este lugar» (Tizón, 1998a: 403), tal como se lee en el comienzo de su segunda novela, El cantar del profeta y el bandido, cuya acción se sitúa temporalmente luego del combate de Quera, al que se alude en más de una ocasión, y la llegada del ferrocarril a La Quiaca (tanto el ferrocarril como el camino, símbolos ambos de progreso, tendrán en la obra tizoniana una valoración ambigua, como veremos a propósito de El hombre que llegó a un pueblo).

Otro elemento de continuidad con la novela anterior está dado por el hecho de que uno de los personajes principales, el contraventor Rosendo López, se presenta como hijo de la Cruceña y el mayor López ya mencionado, que había lanceado en un ojo a un hombre en el combate de Quera.

En este texto, del mismo modo que en El hombre que llegó a un pueblo, encontramos cabalmente presente el conflicto ya mencionado entre los «asideros ortodoxos de la fe que propone el orden eclesiástico» (Amar Sánchez y otros, 1982: 639) y la religiosidad primitiva que domina ese medio, con todas las variantes de la superstición y la leyenda. En este caso, el texto nos ofrece una reconstrucción polifónica y ambigua de dos figuras aludidas: el bandido Ubenceslado Corimayo, muerto y resucitado, y el profeta Pelayo, que asume la estatura mesiánica de un redentor, bien que grotescamente realzada.

Formalmente dividida en dos partes, la novela se inicia con la llegada del párroco a Ramayoc, y finaliza con su partida. Este hecho configura de algún modo el fin de todo el pueblo.

«Estableciendo una relación de simetría con la figura del párroco, se sitúa, también en ambos extremos del relato, la imagen del Comisionado, quien, sentado a la puerta de su almacén, contempla el desfile de la historia por la calle mayor de Ramayoc y asume la función de cronista» (Amar Sánchez y otros, 1982: 640). A través de su conciencia se focalizan mayoritariamente los relatos de la segunda parte, mientras que la primera corresponde a la enunciación del Contraventor que -como testigo ocular- expone su versión de la historia, que es continuamente contradicha por otras voces o por él mismo. Su relato contribuye a delinear las figuras aludidas en el título de la novela, en un juego entre lo sagrado y lo profano, entre el mito y la historia, «entre las motivaciones y determinaciones reales y las entidades que plasma la superstición y la leyenda» (Amar Sánchez y otros, 1982: 640), entre la geografía real y la mítica.

Pero el mundo novelesco de Tizón no es solo espacio, sino también tiempo, historia. Los críticos han puesto de relieve las particularidades de este «buceo en un pasado no inmediato, y a la vez fantasmagórico, donde la búsqueda histórica se encabalga con el rescate de elementos míticos» (Amar Sánchez y otros, 1982: 636). Del mismo modo se relaciona esta actitud de «universalización» de la historia local con «la intensa preocupación por el rescate de una cultura sumergida» (Amar Sánchez y otros, 1982: 636).

Así, entendemos por qué de la gesta emancipadora solo se rescate en la narrativa tizoniana el episodio del denominado «Éxodo jujeño» de 1812, tal como ocurre en Sota de bastos, caballo de espadas (considerada su novela más propiamente histórica), y que este hecho histórico -aun siendo fundamental para el desarrollo de la trama- quede subsumido en la problemática individual de sus personajes, envueltos en una aventura que tiene mucho de realismo mágico y también del componente bíblico, que es otro de los ingredientes del trasfondo ideológico de la obra de Tizón. En este caso, la idea de una profecía, un Precursor y un Mesías con la marca de una estrella en la mano campea por las páginas, entretejida con las alternativas de la lucha contra las fuerzas realistas.

La novela se divide en dos partes. La primera, titulada «Pulperos, caballeros, pordioseros» (tomado de la expresión popular que detalla la parábola social de los conquistadores en estas 
tierras), presenta los hechos anteriores al momento crucial del abandono e incendio de la ciudad, aunque se concentra en la historia de Teotilde y Manuel de Urbata, padres de un niño que se marchó tras un cerdo blanco y que retornará -luego de presenciar el ajusticiamiento de Tupac Amaru- trayendo ocultos ciertos documentos desde Chuquisaca.

La segunda parte, titulada «El centinela y la aurora» es la que narra el episodio histórico propiamente dicho, ero envuelto en una proliferación de otras historias que adensan y complejizan el espesor semántico del texto, casi como relatos autónomos, en los que la multiplicidad de versiones crea un efecto de desconcertante ambigüedad.

A continuación, y en orden a ocuparnos solo de la narrativa puneña de nuestro autor, podemos ubicar la novela breve El hombre que llegó a un pueblo (1988), texto que pertenece, al decir de los críticos, a una etapa de cambio en la escritura tizoniana; ya que -como afirma Leonor Fleming- «Tizón va dejando atrás la visión romántica de una arcadia perdida, recuperada en el cantar, en la leyenda o en la escritura, mientras se extingue en la realidad» (Fleming, 1993: 6), al par que se abre a una nueva evaluación de la llegada del progreso a la zona norteña, «juzgada no ya en términos axiológicos, sino como un hecho inevitable que importa pérdidas y ganancias» (Massei, 1993: 112).

En efecto: el tema de El hombre que llegó a un pueblo es, en primera instancia, el choque entre una sociedad clausa, tradicional, encarnada en ese «pueblo» aludido por el título y los potentes vientos de renovación que amenazan con aventar toda esa forma de vida, representados por los hombres que vienen a construir un camino, símbolo de apertura. Se verifica así un contraste cultural que ha sido frecuentemente señalado en la narrativa de Tizón y que reconoce como instancias contrapuestas el primitivo mundo andino, con fuerte impronta indígena, y el mundo de la civilización, el mundo letrado de las ciudades ${ }^{15}$. Esa suerte de dicotomía centro / periferia se traslada a la escritura y, así, frente a la realidad de la Puna «que es percibida como agonía, desintegración y muerte de la cultura, la historia y hasta de la misma sociedad, Tizón elabora su novelística utilizando los materiales que encuentra en la tradición cultural puneña, por un lado, y por el otro, los procedimientos y recursos que la serie de la narrativa transculturadora le provee» (Tendler, 1989: 158).

De todos modos, una lectura más profunda del texto que nos ocupa, como de otros de Tizón, nos permite advertir que -bajo el aparente problema bicultural- subyace algo más: una peculiar visión de la condición humana que -enraizada en un entorno regional y aun condicionada por él, supera ampliamente la problemática aludida. Vale decir que el enfoque transculturador debe ser complementado por otra indagación diferente, y que tienda a desentrañar ciertas constantes significativas, de naturaleza claramente axiológica, cuando no religiosa.

El forastero que llega al pueblo huyendo de la cárcel dibuja un itinerario de búsqueda, que en primera instancia es la de alejarse de la prisión -física, real-, si bien esta decisión no aparece desde el comienzo como un bien valorado: «no estuvo entusiasmado [...] o no quería estarlo»;

15 Elida Tendler habla, a propósito de Tizón, de una escritura «transculturadora» (en la terminología de Angel Rama) en tanto sus textos «recuperan áreas de significación que habían sido desdeñadas y descartadas por la tradición (literaria y cultural) hegemónica argentina, de ahí el hecho de que se presenten como desagraviando las interpretaciones reductivas y selectivas, en nombre de una contracultura, de una cultura considerada arcaica, es decir, desactivada históricamente e improductiva en la actualidad. En esta recuperación y conexión con un pasado que había sido olvidado, dejado fuera de la memoria histórica nacional, Tizón realiza distintas operaciones de acceso y rescate: procede básicamente a reinterpretar esa zona de representación y significación, a desafiar las formas que sostienen la versión oficial y elaborar un discurso narrativo técnicamente moderno. Su trabajo sobre el lenguaje y la construcción del texto se orienta hacia el mantenimiento de la percepción y la mirada identificadas interiormente con esa cultura tradicional» (1989: 158-159). 
«le daba igual», son algunos de los sintagmas que contribuyen a sustentar esta afirmación de un estado de indefinición por parte del personaje, que se considera a sí mismo como «forastero de camino hacia ningún lado» (Tizón, 1998b: 463), que «llegara involuntariamente al pueblo» (Tizón, 1998b: 470), como término de un «viaje sin destino, hasta ahora» (Tizón, 1998b: 439).

La pintura del pueblo es en sí misma la de esa decadencia reiteradamente aludida, y puede ser la de cualquiera de estos pueblos puneños en la actualidad (quizás hasta corregida y aumentada): «Aquel pueblo tenía por entonces cuarenta y seis casas de adobe-como la iglesia-con sus cocinas, cobertizos y corral; diecinueve de ellas habitadas; a dos mil quinientos metros sobre el nivel del mar y aislado entre montañas» (Tizón, 1998b: 437).

Este mundo reúne muchas de las características que se señalan a propósito de la novela $\mathrm{La}$ peste, del escritor existencialista Albert Camus: similar mundo estático y encapsulado, en el que la historia es una suma de acontecimientos sin orden intrínseco; la epidemia es una de las formas de expresión de un mal puro e infundado que conduce a la constatación de nuestra condición absurda y, por lo tanto, a una ética tan atemporal.

La idea de azar y de indiferencia valorativa que ha parecido imponerse al comienzo dela novela El hombre que llegó a un pueblo ${ }^{16}$, se convierte cada vez más en una reflexión sobre esa misma condición precaria del ser humano y sobre la vacuidad de las relaciones interpersonales (tema de la máscara, del doble). Así, el hombre, junto a los habitantes del pueblo -esos hombres solitarios, duros y ásperos como la tierra que habitan-busca una respuesta que atañe en última instancia al sentido del mal y al valor de la libertad humana en un mundo herido, degradado. Y es aquí donde el hipotexto bíblico se entreteje admirablemente, en la novela de Tizón, con circunstancias histórico-geográficas concretas: la realidad de un territorio largamente marginado, habitado por los derrotados de una batalla librada no ya contra los invasores y enemigos, sino contra la pobreza, la injusticia y el olvido, que repite a escala regional el drama universal de una realidad caótica.

Estos personajes se debaten en la absoluta soledad y en la mayor resignación y perciben agudamente la falta de libertad, pero no entendida en el sentido de «libertad política» (ya que ni siquiera la lucha por la independencia aludida en Sota de bastos, caballo de espadas, como veremos, parece ofrecer alguna esperanza), ya que este concepto resulta demasiado abstracto para hombres cuya principal preocupación es la supervivencia en lucha con ese medio hostil, que adquiere el valor de «lo tenebroso», enunciado por Kusch, según señalamos anteriormente. Y tampoco parece existir para ellos la capacidad de libre determinación (ni la libertad de actuar ni la de elegir): «Vivir es moverse, y ya no te podís mover. Y yo me puedo mover pero no sé para dónde» (Tizón, 1998b: 319), sino una especie de condicionamiento ontológico que los convierte en seres atados a un destino, en la que el concepto mismo de libertad parece ser cuestionado, puesto en discusión.

\section{El tema de la libertad}

En la novela El cantar del profeta y el bandido hay un pasaje que resulta clave en relación con el planteo del tema de la libertad:

-Yo no quiero esto; no lo resisto. Me voy.

-Usted es libre, señor, usted puede irse...

16 A partir de una definición temporal como la siguiente: «Algunos cuentan que el comienzo de la historia que se va a narrar sucedió en tiempos del gobernador Oviedo [...] Otros, en cambio, son menos precisos y conjeturan que todo ocurrió antes, cuando los días eran más largos que los de ahora y un mes era como un año y los hombres dormían tan poco como los pájaros» (Tizón, 1998b: 455). 
-iLibre! Como si alguien lo fuera. Nadie es libre; la vida está llena de resistencias, no hay libertad. El funcionario, quizá pensando en su propia vida, contestó:

-¿No tenemos acaso destino? El destino manda y la libertad es igual que el destino. Con solo uno ver estas paredes basta para darse cuenta. Hay libertad para ver; para ir mirando la vida; pero también hay libertad para hacer lo que uno quiera, así dicen.

-Mienten. Hay que separar una cosa de la otra. Perdón pido, pero cagarse en Dios no es un acto de libertad sino un abuso.

-Padre, usted mismo quiere irse y no se irá hasta que llegue esa carta, dígame entonces si no es verdad, como lo tengo visto, que el hombre se hace libre cuando aparece la casualidad.

Solo al cabo de un tiempo, cuando ya estaba el pensamiento volando sobre otros campos, el cura contestó, muy por lo bajo:

-Sí y no. Digo, sí para unos, no para otros. El alma es como una flecha, pero también está la trabazón del cuerpo (Tizón, 1998a: 519).

Aun así la lucha por la emancipación aparece como un hecho de valoración incierta. Es significativo que en Sota de bastos, caballo de espadas -que, como dijimos, es la más propiamente histórica de las novelas de Tizón, y cuyo recorte temporal corresponde precisamente a los años de luchas en el noroeste argentino por asegurar la recién conquistada libertad política- el único episodio textualizado sea el del éxodo jujeño, la orden dada por Manuel Belgrano de abandonar y arrasar la ciudad: un momento de dolor y no de gloria; que lejos de promover el entusiasmo patriótico, lo que genera, al menos en la visión que asumen los personajes dela novela, es la resistencia yla duda:

El bando -tres carillas de lectura- se conoció temprano en la mañana y calló sobre la villa, que ya tenía sus brazos abiertos a la derrota y a la entrega. Avanzaba el enemigo y todo debía ser destruido, incendiado y arruinado para que las tropas nada encontraran a su paso. ¿Pero quién era ese impío que así lo ordenaba? ¿Y en nombre de quién? ${ }^{17}$ (Tizón, 1998b: 139).

Seguramente Tizón se propone relatar los hechos que atañen especialmente a su «patria chica», pero en esa historia hubo también momentos de gloria, como los triunfos de Salta y Tucumán ${ }^{18}$, obtenidos por el mismo Belgrano, que aparece como personaje en la novela, pero a quien no se nombra: solo se lo alude como «el caudillo»; se lo evoca en el momento supremo de esta decisión que afectará la vida de muchas personas:

En una habitación de paredes desiguales enjalbegadas, gruesas, rugosas, el caudillo, en camisa, pantalones de paño de bayeta blanca y botas, escribe y piensa de a momentos sobre una mesa pequeña [...] El espectáculo de la calle, del mundo, nunca le ha gustado al general; él es un humanista, un teórico de la economía -piensa- acaso un ratón de librerías, y esta carga de soldado le viene mal; pero aún cree que las ideologías son más importantes que la vida, y vuelve a su escritorio. No cambiará una sola palabra del bando, leído ya en todas las esquinas, redobles previos del tambor (Tizón, 1998b: 156-157).

17 Con estas palabras, el narrador parece hacerse eco de lo que «escribía el jefe Tristán a Goyeneche: 'Belgrano es imperdonable por el bando del 29 de julio'. Cuando pasó sus ojos sobre aquel ultimátum le calificó de 'bando impío’» (Carrillo, 1989: 149).

18 En reconocimiento a estos triunfos, se le obsequió a Belgrano la famosa «tarja», actualmente exhibida en el Museo Histórico Nacional: «El objeto en sí [es], una compleja obra de platería, [...] una reunión de piezas desemejantes, formadas por follajes, frutas, flores, animales y figuras humanas, que se yuxtaponen o sobreponen las unas a las otras, para constituir un todo, proporcionado y esbelto en sus líneas generales, sin duda alguna, pero fantasioso y desconcertante en su composición». En: http: //arimlunapiedrasyzafiros. blogspot.com/2010/06/la-tarja-de-potosi.html. 
La idea que parece destacarse en esta especie de soliloquio del personaje es el peso de la ideología por sobre la realidad. Para el hombre concreto, el de esta zona, la verdad está en la tierra, en el aferrarse a lo propio, en el «estar»: «Él lo ha soportado casi todo: perdió su vaca, su casa, su mujer, su jefe, pero no quiere irse; el solo pensamiento de vagar por lados que no conoce hace que tiemble el cuerpo y se niegue a andar» (Tizón, 1998b: 351). Recordemos lo dicho anteriormente, en relación con el pensamiento del filósofo Rodolfo Kusch, cuando afirma que la cultura quichua era profundamente estática y era el suyo un estatismo que abarcaba todos los aspectos de la vida, que giraba en torno del estar aquí, vale decir, el vivir aferrado a una naturaleza -aun hostil- y a una determinada organización política y social. Este mundo estático se inmoviliza «en el esquema mágico que ha hecho de la realidad» (Kusch, 1962: 194).

La guerra es sentida como ajena: «-Se equivoca, mi coronel -dice el otro, aunque parece no hablar-. Esta guerra es solo suya, no nuestra. Nosotros solo morimos» (Kusch, 1962: 293). Únicamente en boca del personaje del hijo perdido, el hombre señalado por una estrella en la mano, parece expresarse la adhesión a las ideas emancipadoras: «'No hay hombre que tenga una razón para arrodillarse delante de otro', dije. 'Y lo que es bueno para un hombre debe ser bueno para un pueblo'» (Tizón, 1998b: 79). Pero se trata de una formulación muy general, que no halla eco en el sentir del conjunto de los pobladores, para quienes tales «rencillas» aparecen más bien como ajenas, cuando no perniciosas, como si la vida real pasase por otro lado, tal como manifiesta doña Teotilde, la madre del elegido: «Esta tierra es nuestra, la limpiamos de alimañas y nos pertenece. El conde de Chinchón puede seguir dictando sus ordenanzas que nadie cumple y pueden el rey y la reina seguir hablando en francés y en italiano, que nadie los entiende» (Tizón, 1998b: 84). Los actos heroicos parecen carecer de importancia, como cuando se alude a varios ajusticiados por su adhesión a las ideas de libertad, entre los que se cuenta Tupac Amaru, y otros: «He visto que un hombre en la plaza ha sido ahorcado vivando a la libertad y bien puedo yo morir ahorcado por cosas más importantes» (Tizón, 1998b: 115).

En todo caso, las noticias de estos hechos -ocurridos en España, Lima y la también remota Buenos Aires- llegan lejanas y desvaídas, cuando no tergiversadas: «Se dice que ya no hay gobierno. Que el rey es preso de los franceses y que un grupo de gente bilingüe se ha encaramado al poder después de que los ingleses fueron rechazados en el puerto de Buenos Aires» (Tizón, 1998b: 120).

El problema de la libertad parece relacionarse, en última instancia, con el del «silencio de Dios»:

También el diablo es hablantín.

Se oyó un murmullo y otro, no se supo quién, contestó como para sí:

-Él es libre. No necesita ni de la alegría ni de la pena. Habla clarito por su boca y todos sabimos que ahí está porque su voz es puntiaguda y olorosa. La de Dios ni se oye y todos la confundimos.

-Dios tiene un libro escrito y ni necesita hablar.

-Los pobres no sabimos leer (Tizón, 1998b: 343).

En última instancia, no hay una esencia humana porque Dios no está y todo se resuelve en un caos de existencias concretas:

Soñamos, dicen que aún desvelados soñamos vivir; o que la vida es nada más que una propuesta que, a medida que vivimos o envejecemos, vamos desvirtuando; y luego también está la muerte que intentamos exorcizar con burlas o rezos, con actos gratuitos o solemnes, con el olvido o los 
discursos como formas de simulación. No existe, según parece, la vida ni la muerte. Solo existen vidas y muertes aparentes, como gestos (Tizón, 1998b: 287-288).

A esta misma conclusión parece arribar el hombre que llega al pueblo, luego de algunos «encuentros con la muerte», cuando lo llaman para atender a una anciana moribunda y su «Huerto de los Olivos»: un largo soliloquio en el que reflexiona acerca de la noción de Dios y la libertad humana:

\begin{abstract}
Quizás ya no pueda más -piensa el hombre. Hace mucho que está absorto mirando de pie en el fondo de la casa, donde antes pudo ser el huerto [...] Ellos no son libres, están unidos a sus piedras, viven en un país muerto. Y yo soy un dios impotente, apresado y cautivo por la veneración egoísta de estos locos que sólo ven su salvación en Dios, pero ese dios es como un viejo pez agonizante en una charca (Tizón, 1998b: 499).
\end{abstract}

Y luego, ante la deserción del pueblo: «-Señor: ayúdame como antes me ayudabas. ¿Es cierto que me ayudabas, verdad?» (Tizón, 1998b: 493) y «-¿Qué haré? Me has traído hasta aquí ¿para qué? ¿Qué es lo que podemos ofrecer de mejor? Todavía hay algunos que están dispuestos» (Tizón, 1998b: 494). Tiene también su calvario: la humillación del castigo sufrido a manos del sobrestante que capitanea el grupo de obreros viales, cuando intenta que abandonen el pueblo; el rechazo del pueblo y la experiencia del silencio de Dios («Alguna vez Dios nos manda comer mierda», Tizón, 1998b: 97). Luego de esta derrota, el hombre metido a redentor permanece «tres días en cama» y luego se reintegra a la vida del pueblo, fracasada su intención redentora, como un muerto: «El hombre flaco envejeció como todos y jamás volvió a dirigir la palabra en forma directa a ninguno [...] Al cabo de los años ya casi nadie sabía cómo ni cuándo el hombre había llegado al pueblo. Y aquellos que quizás alguna vez pudieron haber visto en él la voluntad de todos alzándose contra la incuria y el olvido, abrazaron otras causas o se acogieron a otras promesas y consuelos» (Tizón, 1998b: 120).

Del texto se desprende una visión pesimista de la naturaleza humana, que habla de una condena en el tiempo y de la radical ajenidad de Dios. Así, se arrastra una culpa que es inherente a la naturaleza humana y que no puede ser redimida, porque se ha perdido cualquier religación con lo sobrenatural. En eso consiste el error del hombre moderno: querer reconquistar el jardín del Edén con las solas fuerzas humanas. Si se pierde la explicación sobrenatural para el dolor y el sufrimiento, el mundo no tiene sentido, de allí la indiferencia final por parte del hombre y la resignación amarga por parte del pueblo. En todo caso, lo único que subsiste es la inalterable tranquilidad del paisaje:

Bello es el paisaje en este rincón del mundo. La tierra es árida y sembrada de piedras blancas y rojas, pero es verde en los faldeos que van a morir suavemente en las hondonadas donde crecen salvajes la verbena y el poleo. El viento sopla solo en las tardes, pero cuando el aire está quieto el cielo es azul plácido y sin nube y algunas aves lo cruzan de este a oeste. Nadie sabe a dónde van ni de dónde viene. Los pocos árboles del páramo han sido plantados por el hombre y son objeto de una oscura veneración. Aquí amanece más temprano y atardece antes y las sombras que proyectan los peñascos son temblonas y transparentes como el reflejo del agua (Tizón, 1998b: 505).

\title{
5. Conclusiones
}

A través de este somero recorrido por la obra del escritor argentino Héctor Tizón hemos visto cómo, en respuesta a las incitaciones epocales, pero también al peso de toda una cosmovisión 
arcaica -transmitida por sus niñeras aborígenes, que le legan también esa oralidad penetrada de quichuismos- como reiteradamente manifestara, se va configurando un orbe narrativo original y denso, expresado en un lenguaje también propio.

Esta elección, como recuerda reiteradamente Leonor Fleming, crítica literaria y amiga del escritor, no significa de ningún modo la caída en «el vicio del regionalismo, del color local y del folklorismo» (Tizón, 1996: 120). De todos modos, el paisaje puneño persiste y pervive en su narrativa. En el artículo «Más allá del regionalismo: la transformación del paisaje», Foffani y Manzini escriben: «El paisaje no es el marco que encuadra la historia o a los personajes; el paisaje es la historia misma, porque así como el personaje engendra el paisaje, en un movimiento de endogénesis, también los personajes y sus historias sólo pueden ser concebidos en ese paisaje» (Foffani y Mancini, 2000: 279).

En esta suerte de determinismo geográfico, los personajes tizonianos arrastran una existencia en la que el concepto mismo de libertad es puesto en cuestión en reiteradas ocasiones, en la concepción pesimista de un dejarse estar que no parece tener horizontes:

La costumbre de vivir, el impulso, la inercia, le mantenían en este mundo. Y la vida era esa música profunda de compases apagados [...] serpentinas de viento, goterones; viento sobre los hechos, hálito de las siestas; tronar del cielo. Era el flujo dorado. Era el Tiempo. Fuerza invisible y lenta que corroe, debilita, acumula, destruye. Que entorpece el ala de las aves, licúa las osamentas de los muertos, que seca los ojos (Tizón, 1998b: 346). 


\section{Bibliografía}

$\searrow \quad$ AMAR SÁNCHEZ, Ana; STERn, Mirta; ZUBieTA, Ana (1982). «La narrativa entre 1960 y 1970. Di Benedetto, Tizón, Moyano y Hernández». In: Historia de la literatura argentina, Tomo 5. Buenos Aires: Centro Editor de América Latina, pp. 625-648.

У ASTRADA, Carlos (1949). «El existencialismo, filosofía de nuestra época». In: Actas del Primer Congreso Nacional de Filosofía. Mendoza: Facultad de Filosofía y Letras-UNCuyo, tomo I, pp. 349-358.

У BORDA de ROJAS PAz, Nerva (1986). «Kusch: expresión de una estética americana». In: MATURo, Graciela et al. Literatura y hermenéutica. Buenos Aires: Fernando García Cambeiro.

У CAMPoy, Emiliano Matías (2018). «Héctor Tizón: el arte como ejercicio de la libertad». Landa, 7.1, pp. 304-322.

У CARRILlo, Joaquín (1989). Jujuy. Apuntes de su historia civil. Jujuy: Universidad de Jujuy.

ע CASTELlino, Marta (2002). «El tema del mal, la redención y la culpa en El hombre que llegó a un pueblo de Héctor Tizón». In: Hispanismo en la Argentina; Los portales del siglo XXI. San Juan: Universidad Nacional de San Juan.

У Coly, Youssoup (2012). «Claves del existencialismo en la novela En vida de Haroldo Conti». Anales de Literatura Hispanoamericana, 41, pp. 345-364. https://doi.org/10.5209/rev_ALHI.2012.v41.40308

У ECHEgoyen olleta, Javier (1997). Historia de la Filosofía. Volumen 3: Filosofía Contemporánea. Madrid: Editorial Edinumen. https://www.e-torredebabel.com/Historia-de-la-filosofia/Filosofiacontemporanea/Sartre/Sartre-Angustia.htm

У FLEMING, Leonor (1993). «Centros y periferias. Una voz de fronteras: Héctor Tizón». Diálogos 2, pp. 6-8.

У FLEMING, Leonor (1996). «Diálogos entre novelistas argentinos y españoles (presentación)». Revista de Occidente, 179, Madrid, pp. 79-84.

\ FLEMING Leonor. (2006). «La narrativa de Héctor Tizón: una lengua de frontera». In: Viejas y nuevas alianzas entre América Latina y España, España: 1620-1627. https://halshs.archives-ouvertes.fr/halshs-00104678.

У FOFFANI, Enrique; MANCINI, Adriana (2000). «Más allá del regionalismo: la transformación del paisaje». In: DRUCAROFF, Elsa. «La narración gana la partida», vol. 11 del ciclo Historia crítica de la literatura argentina. Buenos Aires: Emecé, dirigido por Noé Jitrik, pp. 261-288. KUSCH, Rodolfo (1962). América profunda. Buenos Aires: Librería Hachette. KUSCH, Rodolfo (1966). Indios, porteños y dioses. Buenos Aires: Stilcograft.

KUSCH, Rodolfo (1977). El pensamiento indígena y popular en América. Buenos Aires: Hachette. KUSCH, Rodolfo (1978). Esbozo de una antropología filosófica americana. Buenos Aires: Ed. Castañeda. LAGMANOVICH, David (1974). La literatura del noroeste argentino. [s.l.]: Editorial Biblioteca. MASSEI, Adrián (1998). Héctor Tizón; Una escritura desde el margen. Córdoba: Alción Editora.

Niborski, A. (2919). «Rodolfo Kusch». Letra urbana, Revista digital de cultura, ciencia y pensamiento. http://letraurbana.com/articulos/rodolfo-kusch/

У PAZ, Octavio (1971). Posdata. México: Siglo XXI.

У PÉREZ, Alberto Julián (2003). «El pensamiento de Rodolfo Kusch: una manera de entender lo americano». Mitológicas, Vol. XVIII, Buenos Aires, pp. 59-66.

У TENDLER, Elida (1989). «La configuración del paisaje, una operatoria transculturadora en la escritura de Héctor Tizón». In: Cuadernos de Literatura, 4, Facultad de Humanidades, Universidad Nacional del Nordeste. https://doi.org/10.30972/clt.043309

У Tizón, Héctor (1996). «Equívocos». Revista de Occidente, 179, Madrid, pp. 120-125.

У TIZón, Héctor (1998a). Obras escogidas. I Cuentos y novelas. Buenos Aires: Perfil libros.

У TIZÓN, Héctor (1998b). Obras escogidas. II Novelas. Buenos Aires: Perfil libros.

У TIzón, Héctor (1998c). Tierras de frontera. Jujuy, coedición de la Universidad Nacional de Jujuy y la Secretaría de Cultura de la Provincia. La versión ampliada fue editada por Alfaguara, en Buenos Aires, 2000.

y TIzón, Héctor (2000). Tierras de frontera. Buenos Aires: Alfaguara. 


\section{Marta Elena Castellino}

Facultad de Filosofía y Letras de la Universidad Nacional de Cuyo

Centro Universitario

Parque General San Martín

(5500) MENDOZA

República Argentina 